\title{
PhytoLex, bază de date cu nume de plante: rezultate şi perspective
}

\author{
Valeria B. Kolosova ${ }^{\oplus{ }^{\circledR 1}}$, Kira I. Kovalenko ${ }^{\oplus{ }^{\Delta 1,2 \star}}{ }^{\text {, Georgy A. Molkov }}{ }^{\oplus 1}$ \\ ${ }^{1}$ Institutul de Studii Lingvistice, Academia Rusă de Științe, Tuchkov pereulok 9, 199053 Sankt-Petersburg, Rusia \\ ${ }^{2}$ Universitatea Europeană din Sankt-Petersburg, Gagarinskaya st. 6/1A, 191187 Sankt-Petersburg, Rusia
}

\section{Despre articol}

Istoric:

Primit 17 septembrie 2021

Acceptat 7 octombrie 2021

Publicat 12 decembrie 2021

Cuvinte-cheie:

lexicologie istorică

semantică istorică

literatură veche

literatură religioasă

etnolingvistică

\begin{abstract}
Rezumat
Numele de plante ruseşti reprezintă un grup semantic slab reprezentat în dicționarele istorice. Baza de date PhytoLex a fost creată în cadrul proiectului „Fitonime ruseşti sub aspect diacronic (secolele XI-XVII)" (2017-2020). Această bază de date conține nume de plante identificate în textele ruseşti din secolele XI-XVII. Elaborarea bazei de date a fost însoțită de cercetări dedicate diverselor aspecte legate de reprezentarea numelor de plante în limba rusă în general şi în relație cu anumite genuri specifice în particular: cărți despre plante, documente ale Cancelariei Spițerilor, documente comerciale, literatura bisericească şi lexicoane. Au fost identificate şi nume vechi de plante necunoscute. Materialele cuprinse în această bază de date vor constitui baza Dicţionarului de nume vechi de plante în limba rusă, pentru care au fost deja elaborate schițele intrărilor. Vom apela la o serie de soluții tehnice pentru a dezvolta o bază de date care să reprezinte numele de plante consemnate în perioadele ulterioare ale limbii ruse.
\end{abstract}

\section{Introducere}

Baza de date PhytoLex (phytolex.iling.spb.ru) a fost elaborată ca rezultat al proiectului „Fitonime ruseşti sub aspect diacronic (secolele XI-XVII)”. Obiectivul proiectului-de a stabili geneza, cronologia apariției, modalitățile de împrumut al numelor de plante din diversele stadii de dezvoltare a limbii ruse-au impus necesitatea creării unei baze de date cu nume de plante în rusa veche.

La debutul proiectului, principiile care au stat la baza creării şi completării bazei de date s-au stabilit pe baza lucrării lui Izmail I. Sreznevsky, „Materiale pentru Dicționarul de limbă rusă veche pe baza monumentelor scrise”. Procesarea materialelor a evidențiat o serie de aspecte problematice: 1) identificarea plantelor (traducere îndoielnică sau lipsa traducerii); 2) identificarea sursei; 3) numeroase greşeli de scriere în citate; 4) momentul intrării în limbă a unui fitonim; 5) chestiuni legate de reprezentarea grafică (particularități de scriere a cuvintelor şi caracterelor: title, litere scrise deasupra rîndului etc.); 6) căutarea automată a cuvîntului în bazele de date existente; 7) absența dicționarului invers (rusă - rusă veche) (Kolosova, 2017). Am înțeles astfel că pentru reprezentarea numelor de plante în baza de date este necesară o muncă de cercetare asiduă, atît pentru a investiga sursele bazei de date, cît şi pentru a stabili principiile implementării tehnice. La finalul proiectului, participanții au elaborat o serie de aproximativ 20 de articole dedicate acestor aspecte; unele dintre observații au rămas nepublicate. Principalele rezultate ale acestui demers de cercetare vor fi prezentate în cadrul prezentului studiu.

\section{Nume de plante în diverse genuri}

Textele ruseşti din secolele XI-XVII aparțin mai multor genuri. În cadrul bazei de date, fiecare text este etichetat în funcție de genul de care aparține, clasificarea genurilor fiind stabilită de membrii proiectului special în scopul cercetării noastre. Distribuția consemnărilor în funcție de gen este indicată în Tabela 1 .

*Adresă de corespondență: kira.kovalenko@gmail.com. 
Valeria B. Kolosova, Kira I. Kovalenko, Georgy A. Molkov

\begin{tabular}{ll} 
Gen & Număr de consemnări \\
\hline Biblia canonică & 832 \\
\hline Cărți de predici & 9 \\
\hline Scrieri teologice & 83 \\
\hline Texte hagiografice & 127 \\
\hline Scrieri apocrife & 13 \\
\hline Lucrări enciclopedice & 9530 \\
- tratate de agricultură & 442 \\
- cărți de botanică (în special despre plante medicinale) & 632 \\
- lucrări de geografie & 657 \\
- lexicografie & 7255 \\
$\quad$ - lexicoane & \multicolumn{2}{c}{5803} \\
$\quad$ - ghiduri de conversație & 1452 \\
- lucrări de medicină & 201 \\
\hline Documente comerciale & 5086 \\
- Cancelaria Spițerilor & \multicolumn{2}{c}{3297} \\
- Cancelaria Ambasadei & \multicolumn{2}{c}{107} \\
Scrieri istorice & 92 \\
Scrisori & 34 \\
Ziare & 11 \\
Ficțiune & 208 \\
Altele & 602 \\
\hline
\end{tabular}

Tabela 1: Distribuția consemnărilor în funcție de gen

Cel mai mare număr de consemnări provine din documentele comerciale, în special de la Cancelaria Spițerilor, precum şi din lexicoane, ai căror autori au utilizat o gamă largă de surse pentru elaborarea intrărilor. Tratatele originale ruseşti de plante medicinale au apărut abia în secolul al XVII-lea, însă, deşi baza de date nu include un număr mare de astfel de lucrări, acestea conțin informații extrem de interesante legate de plantele utilizate în medicină. Lucrările biblice şi religioase, precum şi textele teologice şi hagiografice furnizează cele mai vechi consemnări. Unele dintre acestea datează din secolele IX-X, perioadă în care se presupune că au apărut primele lucrări în slavona bisericească ${ }^{1}$. În cadrul bazei de date PhytoLex acestea sînt reprezentate de traduceri vechi ale celor patru Evanghelii, de Catehezele mistagogice ale lui Chiril al Ierusalimului, Hexameronul lui Ioan Exarhul şi Viaţa Marelui Martir Irene al Macedoniei.

\subsection{Literatura bisericească}

Deşi în diversele genuri ale literaturii bisericeşti numele de plante apar doar sporadic, însumate, acestea pot constitui un corpus consistent şi variat. În unele cazuri, textele bisericeşti furnizează consemnările cele mai timpurii ale fitonimelor-cunoscute din alte surse, exotice şi relativ rare în scris. Cu precădere în diverse Hexameroane au fost identificate numele диктамонъ (Origanum dictamnиs L.), ластовникъ (Chelidonium majus L.), брестие (Ulmus glabra Huds.), дрянььни, дргоньнии, дргннь (Cornus mas L.) etc. Traducerea Vieții Sfintului Andrei cel Nebun pentru Hristos conține primele consemnări pentru Øacyль (Phaseolus spp.), iar traducerea lucrării lui Iosif Flavius Cărți ale Istoriei războiului evreilor împotriva romanilor menționează кипръ (Lawsonia inermis L.) şi мyровалнъ (Balanites aegyptiaca (L.) Delile).

O importanță aparte o au numele de plante menționate în Evanghelie. Istoria traducerii slave a acestui text, care a inclus mai multe etape de editare în regiunea slavă sudică înainte de a ajunge în Rusia, a condus la existența unui număr semnificativ de versiuni lexicale (Slavova, 1989, p. 15-16), inclusiv la variante

\footnotetext{
${ }^{1}$ Fiecare sursă conţine două date: anul în care a fost creată sursa, care uneori este ipotetic, şi anul în care a fost realizată copia utilizată pentru selectarea consemnărilor.
} 
diferite ale fitonimelor incluse. Baza de date PhytoLex include materiale din majoritatea celor mai vechi şi semnificative copii ale Evangheliei, reprezentînd textul traducerii lui Chiril şi Metodiu cu diversele modificări: cele Patru Evanghelii (sau Tetra, în care pericopele din evanghelişti urmează numerotarea capitolelor) şi Lecționarul Evanghelic (sau Aprakos, în care pericopele apar în ordinea citirii în timpul liturghiei pe parcursul anului liturgic); Lecționarul, la rîndul său, a fost împărțit în variante prescurtate şi variante complete (Zhukovskaya, 1968; Temčinas, 1989, p. 12-13). Comparația între diferite tipuri de Evanghelie indică faptul că traducerea timpurie în slavonă era o compilație de texte traduse din greacă în perioade diferite (Temčinas, 2013, p. 71).

Materialele cuprinse în baza de date PhytoLex reflectă acest caracter eterogen al textului evanghelic: plante precum Ficus sycomorus L., Ficus carica L., Aquilaria spp., Anethum graveolens L., Mentha longifolia (L.) Huds. sînt reprezentate în două sau mai multe moduri. Astfel, Ficus sycomorus L. (sicomor) are două

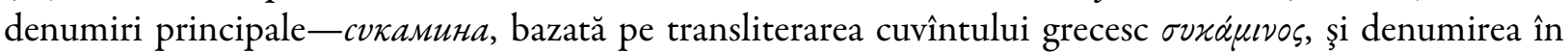
slavonă ягодичина; legătura acestora cu diferitele etape ale editării textului evanghelic a fost deja indicată în cercetările efectuate de Slavova (1989). Materialul inclus în baza de date ne permite să observăm că această distribuție se păstrează nu numai pentru сvкамина şi ягодичина, ci şi pentru variantele modificate ale acestora: сvкамина, сюкамина şі сvкамня sînt opuse variantelor ягодичина şі ягодина, care sînt reprezentate doar în Lecționarele evanghelice complete-Evanghelia Mstislav (Muzeul de Istorie al Statului, Sin. 1203), Evanghelia Muzeului (Biblioteca de Stat a Rusiei, Rum. 104), Evanghelia Simonov (Biblioteca de Stat a Rusiei, Rum. 105) şi Evanghelia Dobrilov (Biblioteca de Stat a Rusiei, Rum. 103). Cuvintele care denumesc smochinul (Ficus carica L.) se pot identifica în mai multe lecturi din Evanghelie. În majoritatea lor, variantele смоковьница și смокь au utilizare specifică: смокъ este tipic Lecționarelor evanghelice complete $(M t, 21,20 ; 24,32 ; M c, 11,21 ; 13,28 ; L c, 13,6 ; 13,7)$; în In, 1, 48, versiunea смокы a fost identificată şi în Evanghelia Ostromir (Biblioteca Naţională a Rusiei, F.n. I.5), care conține textul Lecționarului Evanghelic scurt. În acelaşi timp, cuvîntul смоковъница rămîne neutru în ceea ce priveşte tipul de text-se regăseşte atît în cele Patru Evanghelii, cît şi în Lecționare. Distribuția inițială a denumirilor pentru mentă (Mentha longifolia (L.) Huds.) poate fi observată în $L c, 11,42$, unde varianta lexicală вонялиц a a fost înregistrată doar în copiile Lecționarului evanghelic complet; distribuția nu poate fi trasată în $M t, 23,23$.

\subsection{Lexicons}

Lexicografii din secolul al XVII-lea au prezentat un viu interes pentru plantele exotice şi numele acestora. Ele au fost incluse în lexicoanele manuscrise alături de descrieri ale aspectului lor şi ale modului în care erau utilizate în viaţa de zi cu zi, în medicină şi în cadrul practicilor religioase. Avînd drept surse lexicoanele elaborate ulterior, autorii au copiat materialele şi au adăugat noi intrări, între care şi nume de plante. Una din sursele cele mai populare a devenit dicționarul de expresii rusesc-grecesc din secolele XIV-XV. Deşi conținea cuvinte greceşti transliterate care nu se numărau printre împrumuturile în limba rusă, autorii au introdus aceste materiale în lexicoane, astfel că cititorii ruşi din secolul al XVII-lea cunoşteau echivalentele greceşti ale termenilor ruseşti виноградъ 'viță-de-vie', pena 'nap', тьıква 'dovleac', редька 'ridiche', чеснок 'usturoi', лукъ 'ceapă, укропъ 'mărar', шафранъ 'şofran' etc. Alte nume de plante (care ocazional apar însoțite de descrieri) au fost preluate în mare parte din texte care erau foarte cunoscute la acea vreme: Sfînta Scriptură, literatură hagiografică şi patristică, texte geografice şi istorice. Un călugăr de la mănăstirea Solovki, Serghei Shelonin, şi-a completat lexiconul în principal prin adăugarea intrărilor de cuvinte preluate din operele literare pe care le-a editat la vremea respectivă (Kovalenko, 2018, p. 199-234). Astfel, au fost incluse descrieri ale unor plante reale sau nume de plante misterioase, precum:

- nuci de cocos („nuci indiene”) - din Topografia Creştină de Cosmas Indicopleustes,

- cedru - din Cronicile lui George Hamartolos,

- copacul istiri „care străluceşte precum soarele” şi ardeii - din Cronograful Rusesc,

- iarbă de scorbut (Smilax?) - din Patericonul de schit, 
- cuișoare, cardamom, scorțişoară, ardei, porumb, smochine, Myristica fragrans şi unele plante neidentificate - din Cosmografie (traducerea rusească a Atlasului lui Gerardus Mercator) (Kovalenko, 2020).

După finalizarea celei de-a treia ediții a lexiconului, Serghei a inclus un număr însemnat de nume de plante provenite din traducerea lucrării Medicinarius a lui Hieronymus Brunschwig. El a transcris toate numele de plante pe care le-a identificat în respectiva lucrare în spațiul liber special destinat pentru subdiviziunea literelor (lista întreagă a intrărilor apare ca supliment la Kovalenko, 2017), astfel că cititorii ruşi s-au familiarizat cu terminologia botanică europeană din perioada respectivă.

\subsection{Documente comerciale}

Un alt grup important de surse care conțin un număr semnificativ de nume de plante este cel al documentelor comerciale, în special al documentelor de la Cancelaria Spiţerilor din secolele XVI şi XVII. Aceste documente indică faptul că în acea perioadă intrau în uz din ce în ce mai multe fitonime. Se preferau denumirile farmaceutice latine, apărute cu mult înainte de nomenclatura ştiințifică botanică. Grupul lexical de nume de plante s-a format într-o perioadă relativ scurtă şi a devenit un fel de material pregătitor (Olekhnovich, 2018a). În plus, textele medicale în limba latină au avut un impact semnificativ în formarea genului prescripțiilor medicale, mai ales în ceea ce priveşte structura acestora (Olekhnovich, 2018b).

Pe lîngă autoritățile ruseşti, şi alte personalități străine de rang înalt apelau la serviciile Cancelariei Spițerilor. Kirill S. Khudin a studiat corpusul de prescripții medicale emise pentru Prințul Valdemar al Danemarcei în timpul călătoriei acestuia la Moscova în 1644-1645. Articolul cuprinde lista alfabetică a plantelor utilizate de Cancelaria Spițerilor, cu atribuirea terminologiei botanice moderne şi însoțită de analiza stării fizice şi a caracterului complet al materialelor-sursă studiate (Khudin, 2013).

Documentele legate de stabilirea granițelor între loturile de teren sînt de asemenea semnificativ reprezentate în baza de date PhytoLex, avînd în vedere faptul că arborii şi arbuştii serveau adesea ca elemente de marcare a granițelor. Documentele cu privire la granițe sînt datate cu precizie şi se atribuie geografic unei anumite regiuni, ceea ce ne permite să determinăm atît zona de unde provine cuvîntul, cît şi zona de unde provine planta desemnată de respectivul cuvînt. Astfel, o comparație între două documente din districtul Uglich a indicat distribuția unor nume de plante, precum şi adjectivele derivate din acestea (Shchekin, 2018).

\subsection{Atlase}

O serie de plante menționate în atlase au fost analizate de către Alexandra B. Ippolitova, printre care: трава с откушенньцм корнем (,iarbă cu rădăcina muşсаtă”), плакун (plakun), адамова голова („,capul lui Adam”), коровий языє („limba-vacii”) and чертогрыљз („mușcătura diavolului”) (Ippolitova, 2018a,b, 2019). De pildă, pe baza textelor despre plantele трава с откушенным корнем (,iarbă cu rădăcina muşcată”) şi a corespondentelor lor vest-europene, am reuşit să identificăm această plantă ca fiind Succisa pratensis. De asemenea, sursa primară a acestor legende s-a dovedit a fi incunambulul din 1492 „Gaerde der suntheit” (Ippolitova, 2018a). În cazul ierbii plakun, lucrurile sînt mult mai complicate: planta menționată ar putea fi Lythrum salicaria, Lythrum virgatum L., Epilobium angustifolium, Adenophora liliifolia Ledb., Iris sibirica L., Succisa pratensis Moench., şi Veronica longifolia L. (Ippolitova, 2019).

Pe lîngă informațiile despre utilizarea plantelor în medicina tradițională, atlasele furnizează informații rare despre modul în care autorii şi-au imaginat aspectul plantelor descrise. Pe baza a peste 2000 de ilustrații s-a demonstrat că imaginile plantelor din lucrările traduse şi din atlasele „populare” se bazau pe abordări fundamental diferite. Dacă atlasele traduse făceau un fel de „portret” al plantelor individuale, în atlasele „populare” plantele erau ilustrate în mediul lor natural. Cei care ilustrau lucrările traduse copiau gravuri europene, adăugînd uneori maniera lor proprie şi mult mai familiară de descriere. Artiştii care ilustrau atlasele „populare” lucrau la aceste ilustrații în mod independent, dar acționau şi conform stilului obişnuit, tipic pentru manuscrisele „comune” (Ippolitova, 2018c). 


\section{Reprezentare lexicografică}

În cadrul proiectului s-a acordat o atenție deosebită chestiunii reprezentării lexicografice a numelor de plante şi a neajunsurilor detectate în dicționarele istorice de limbă rusă, în unele cazuri fiind posibile diverse clarificări în ceea ce priveşte datele sau sensul unor cuvinte cu ajutorul bazei de date PhytoLex. În plus, există un număr semnificativ de fitonime evidențiate de curînd, care nu sînt reprezentate în aceste dicţionare (Kovalenko et al., 2018; Shchekin, 2019). Acest aspect arată că următorul pas logic după munca de cercetare întreprinsă de membrii proiectului este crearea Dicționarului de nume vechi de plante în limba rusă (secolele XI-XVII). Dicționarul va fi elaborat în Lexonomy-un sistem special de scriere a dicționarelor. Partea de rusă veche-latină va conține cuvintele şi semnificaţia acestora şi va furniza forme, variante de gen, variante fonologice şi ortografice, etimologie, definiție / definiții, ilustraţii şi surse. Materialele pot conține geodate, funcții ale plantelor (medicinale, magice, religioase etc.), semnificații metaforice etc. Partea latină-rusă veche va oferi ocazia de identificare a tuturor numelor unei anumite plante consemnate în rusa veche. Formatul electronic al dicționarului va permite mai multor utilizatori să lucreze simultan, aspect deosebit de important în cadrul unui proiect (Kovalenko \& Kolosova, 2019).

\section{Implementare tehnică}

Baza de date PhytoLex a fost creată pe structură Django; pentru interfaţa web s-a utilizat structura Bootstrap. Datele sînt stocate într-un sistem open-source de baze de date obiect-relaționale, PostgreSQL. Este vorba de o resursă gratuită, deschisă, care poate fi actualizată în mod constant şi care în prezent conține peste 16300 de consemnări de nume de plante.

Chestiunile tehnice au inclus aspecte precum: modelarea datelor, crearea și normalizarea vocabularelor controlate, dezvoltarea unei baze de date și a unei aplicaţii web pentru curatorii de date și utilizatorii anonimi ai proiectului pe web și vizualizarea datelor (Kolosova et al., 2018). Complexitatea structurii bazei de date a fost conferită de varietatea tipurilor de informații: acestea includ date care sînt necesare atît lingviştilor (legate de etimologie, citate în ortografia originală, informații despre limba manuscrisului şi limba străină a originalului în cazul în care aceasta este relevantă, descrierea detaliată a surselor şi referințe la publicarea manuscriselor), cît şi specialiştilor în etnobotanică (citate cu ortografie simplificată, terminologie latină, denumiri ştiințifice în rusă, legături către cataloagele botanice). Deşi cîmpul „nume de plantă” este obligatoriu, se pot include citate care să conțină doar descrierea plantei, furnizînd informația metalingvistică. Pentru confortul utilizatorilor care completează baza de date şi pentru unificarea datelor, am creat un număr de vocabulare controlate, cum ar fi: o listă de limbi, liste de termeni medicali, utilizări ale plantelor, părți ale plantelor, clasificarea botanică a termenilor şi altele. Putem astfel căuta date în mod facil şi avem posibilitatea de a structura informaţia conform cerințelor utilizatorului.

\section{Concluzii}

Baza de date PhytoLex conține informații multidimensionale cu referire la plantele consemnate în scrierile ruseşti din secolele XI-XVII. Varietatea de materiale textuale, incluzînd cărți tipărite, manuscrise realizate pe pergament, pe hîrtie și pe scoarță de mesteacăn, precum și varietatea genurilor a făcut posibilă colectarea şi identificarea parțială a unui număr semnificativ de fitonime. Lexemele ne-originale sînt reprezentate prin variante care indică includerea împrumuturilor în limba rusă. Baza de date oferă, de asemenea, numeroase exemple de nume de plante polisemantice care se găsesc rar în dicționarele istorice. Numeroasele citări din diverse genuri textuale oferă informații extinse asupra modului de utilizare a plantelor în viaţa de zi cu zi, în religie, medicină, bucătărie și alte domenii. Toate aceste aspecte ne îndreptățesc să afirmăm că baza de date PhytoLex reprezintă o resursă valoroasă pentru elaborarea unui Dicționar de nume vechi de plante în limba rusă (secolele XI-XVII). În acest moment, baza de date oferă oportunități pentru compararea vocabularului fitonimic din secolele XI-XVII în funcție de genul de care aparține textul. Pe 
Valeria B. Kolosova, Kira I. Kovalenko, Georgy A. Molkov

viitor, aceste date pot fi utilizate pentru compararea materialului în limba rusă veche cu cel din etapele ulterioare de dezvoltare a limbii ruse.

\section{Bibliografie}

Ippolitova, A.B. (2018a). Аегенда о траве соткушенным корнем в русскойрукописной традиции XVI-XIX вв. [Legend about a herb with a bitten root in the Russian manuscript tradition of the $16^{\text {th }}-19^{\text {th }}$ centuries], în „Живая старина”, (1), p. 6-10, [online].

Ippolitova, A.B. (2018b). Растения с названием Адамова глава в русских рукописных травниках [Plant nате Adamоva glava in the Russian manuscripted herbals of the $18^{\text {th }}-19^{\text {th }}$ centuries], în „Полетата на этнологията: межАу знанието и познанието. 25 години асоциация «ОнгъА»", 16, p. 50-76.

Ippolitova, A.В. (2018c). К истории русской ботанической иллюстрачии: «ученье» и «народньце травники XVI-XVIII веков [Towards a History of Russian Botanical Illustrations: "Learned" and "Folk" Herbals in the Sixteenth to Eighteenth Centuries], în „ВИВАIОӨИКА: E-Journal of Eighteenth-Century Russian Studies”, 6, p. 13-45, Crossref.

Ippolitova, A.B. (2019). Плакун в русских рукописньц травниках XVII - начала XX в. [Плакун (Lythrum Salicaria) in Russian herbal manuscripts $17^{\text {th }}-20^{\text {th }}$ century], în Гора калинова (Биљни свет у традиционалној култури словена), УреА. 3. Карановић, Belgrade / Vilnius, p. 217-249.

Khudin, K.S. (2017). Номенклатура лекарственньх растений в медииинской практике Аптекарского приказа (на материале рецептов для датского королевича Вольдемара 1644-1645 г2.) [Nomenclature of medicinal plants used in the Apothecary Chancery's practices (based on prescriptions issued for Prince Valdemar of Denmark in 1644-1645)], în „Acta Linguistica Petropolitana. Труды Института Аингвистических исследований”, XIII (2), Этноботаника 2: растения в языке и культуре, Наука, Saint Petersburg, p. 395-415, [online].

Kolosova, V.B. (2017). Проблемь анализа фитонимов в «Материалах для словаря древнерусского языка по письменныцм памлтникам» И.И. Срезневского [Problems of phytonym analysis in "Materials for the Old Russian dictionary by written monuments” by I.I. Sreznevsky], în Осипова, Е.П. (еd.), И.И. Срезневский и русское историческое языкознание: опььт и перспективь. К 205-летию со дня рождения И.И. Срезневского: сборник статей Международной научно-практической конференции, 21-23 сентября 2017 г., Ryazan State University, Ryazan, p. 229-235.

Kolosova, V., Zaytseva, K. \& Kovalenko, K. (2018). PhytoLex - the Database of Russian Phytonyms: from Idea to Implementation, în SlaviCorp 2018. 24-26 September 2018, Charles University, Prague. Book of Abstracts, p. 88-90, [online].

Kovalenko, K.I. (2017). “Сказание о пропущении вод” как лексикографический источник ["Das New Distilleir Buch" as a lexicographical source], în „Acta Linguistica Petropolitana. Труды Института мингвистических исследований”, XIII (2), Этноботаника 2: растения в языке и культуре, Наука, Saint Petersburg, p. 416-472.

Kovalenko, K.I. (2018). Азбуковник, Аавида Замарая как источник по русской лексикографии XVII века [David Zamaray's lexicon as a source for the Russian lexicography of the $17^{\text {th }}$ century], PhD Dissertation, Saint Petersburg.

Kovalenko, K.I. (2020). «Трава есть нюкая тако нарищаема»: названия растений в Азбуковнике Сергия Шелонина ["There is some grass, the so-called": plant names in Lexicon by Sergius Shelonin], în Сапожникова, O.C. (ed.), Cергий Шелонин и Аревнерусскал книжность XVI-XVII вв., Альянс-Архео, Moscow / Saint Petersburg, p. 10-41.

Kovalenko, K. \& Kolosova, V. (2019). Old Russian plant names dictionary (the $11^{\text {th }}-17^{\text {th }}$ cc.): Word entries drafts in Gürlek, M., Çiçekler, A.N. \& Taşdemir, Y. (eds), ASIALEX 2019. Proceedings of the $13^{\text {th }}$ International Conference of the Asian Association for Lexicography, Asos Publisher, Istanbul, p. 316-328, [online].

Kovalenko, K.I., Kolosova, V.B. \& Shekin, A.S. (2018). Исторические словари как источники базы данньх русских фитонимов (XI-XVII вв.) [Historical dictionaries as sources of the PhytoLex - Russian phytonyms database $\left(11^{\text {th }}\right.$ $17^{\text {th }}$ cc.)], în Крымова, О.Н., Мызников, С.А., Приёмышева, М.Н. \& Пурицкая, Е.В. (eds), Poсcuйскал академическая лексикография: современное состояние и перспективы развития. Сборник научных статей по материалам Международной научной конференщии, посвященной 70-летию выхода первого тома академического «Словаря современного русского литературного языка», Нестор-История, Saint Petersburg, p. 253-262.

Olekhnovich, O.G. (2018a). Аенотативно-семантические коррелячии при формировании фитонимической лексики (на примере «Аокументов Аптекарского приказа» (XVII в.) [Denotative-semantic correlations in the formation phytonymic vocabulary (on the example of the documents of the Pharmaceutical Order of the $17^{\text {th }}$ century)], în „Современная наука: актуальные проблемы теории и практики. Серия «Гуманитарные науки»”, 12, p. 174-179, [online].

Olekhnovich, O.G. (2018b). Становление и развитие медицинского жанра «сказка» на примере опубликованньх «Аокументов Anтекарского приказа» (XVII в.) [Establishment and development of medical genre «tale» in the documents of the Pharmaceutical Order of the $17^{\text {th }}$ century], în Castellví, J., Zainouldinov, A., Garcia, I. \& Ruiz-Zorrilla, M. (eds), Proceedings of the International Conference on Russian Studies at the University of Barcelona, Trialba Ediciones, Barcelona, p. 1391-1401.

Shchekin, A.S. (2018). Межевьце документы XVI-XVII вв. как источник по истории фитонимической лексики русского s3bık [Documents of land surveying of the $16^{\text {th }}-17^{\text {th }}$ centuries as sources for the history of plants denominations in the Russian language], în „САавянская историческая мексикология и кексикография”, 1, p. 195-201, Crossref. 
Shchekin, A.S. (2019). Об одном малоизученном памятнике русской переводной историко-географической литературь [About one understudied monument of Russian translated historical and geographical literature], în „Русский язык в шкоме”, 80 (4), p. 72-77, [online].

Slavova, Т. (1989). Преславскал редакиия Кирилло-Мефодиевского староболгарского перевода Евангелия [Preslav edition of the Cyril and Methodius Old Bulgarian translation of the Gospel], în „Киримло-Мефодиевские студии”, 6, p. $15-129$.

Temčinas, S. (1991). Аистрибуиия глагольньх разночтений в древнейших славянских списках евангелия и объем первоначального перевода [Distribution of verb variations in the oldest Slavic copies of the Gospel and the volume of the original translation], în Исследования по глаголу в славлнских языках. История славянского глагола, Мовсош, p. 9-41.

Temčinas, S. (2013). Кирилло-мефодиевское протоапракосное Евангелие: структура, состав и богослужебнал функция [Cyril and Methodius Proto-Lectionary of the Gospel: Structure, Composition and Liturgical Function], in Krakowskowileńskie Stidia Slawistyczne, 8, Cyrylometodejski komponent kultury chrześcijańskiej Stowian w regionie karpackim. Historia, tradycje, odwotania, Kraków, p. 49-72.

Zhukovskaya, L.P. (1968). Типология рукописей древнерусского полного апракоса XI-XIV вв. в связи с лингвистическим изучением ux [Typology of manuscripts of the Old Russian full type Lectionary of the $11^{\text {th }}-14^{\text {th }}$ centuries in connection with their linguistic study], în Памятники древнерусской письменности. Язык и текстология, Моsсоw, р. 199-332. 